\title{
Reinforced Demand Side Management for Educational Institution with Incorporation of User's Comfort
}

\author{
Karthick Tamilarasu ${ }^{1}$, Charles Raja Sathiasamuel ${ }^{1, *}$, Jeslin Drusila Nesamalar Joseph ${ }^{2}$, \\ Rajvikram Madurai Elavarasan ${ }^{3}$ (D) and Lucian Mihet-Popa ${ }^{4, *}$ (D) \\ 1 Department of EEE, Thiagarajar College of Engineering, Madurai 625015, Tamil Nadu, India; \\ karthi.ieee@gmail.com \\ 2 Department of EEE, Kamaraj College of Engineering and Technology, Madurai 625015, Tamil Nadu, India; \\ jeslineee@kamarajengg.edu.in \\ 3 Clean and Resilient Energy Systems (CARES) Laboratory, Texas A\&M University, Galveston, TX 77553, USA \\ rajvikram787@gmail.com \\ 4 Faculty of Electrical Engineering, Ostfold University College, 1757 Halden, Norway \\ * Correspondence: charlesrajas@tce.edu (C.R.S.); lucian.mihet@hiof.no (L.M.-P.)
}

check for

updates

Citation: Tamilarasu, K.;

Sathiasamuel, C.R.; Joseph, J.D.N.;

Madurai Elavarasan, R.; Mihet-Popa,

L. Reinforced Demand Side

Management for Educational Institution with Incorporation of User's Comfort. Energies 2021, 14, 2855. https://doi.org/10.3390/ en14102855

Academic Editor: Daniela Proto

Received: 5 April 2021

Accepted: 11 May 2021

Published: 15 May 2021

Publisher's Note: MDPI stays neutral with regard to jurisdictional claims in published maps and institutional affiliations.

Copyright: (c) 2021 by the authors. Licensee MDPI, Basel, Switzerland. This article is an open access article distributed under the terms and conditions of the Creative Commons Attribution (CC BY) license (https:/ / creativecommons.org/licenses/by/ $4.0 /)$.

\begin{abstract}
Soaring energy demand and the establishment of various trends in the energy market have paved the way for developing demand-side management (DSM) from the consumer side. This paper proposes a reinforced DSM (RDSM) approach that uses an enhanced binary gray wolf optimization algorithm (EBGWO) that benefits the consumer premises with load scheduling, and peak demand reduction. To date, DSM research has been carried out for residential, commercial and industrial loads, whereas DSM approaches for educational loads have been less studied. The institution load also consumes much utility energy during peak hours, making institutional consumers pay a high amount of cost for energy consumption during peak hours. The proposed objective is to reduce the total electricity cost and to improve the operating efficiency of the entire load profile at an educational institution. The proposed architecture integrates the solar PV (SPV) generation that supplies the user-comfort loads during peak operating hours. User comfort is determined with a metric termed the user comfort index (UCI). The novelty of the proposed work is highlighted by modeling a separate class of loads for temperature-controlled air conditioners (AC), supplying the user comfort loads from SPV generation and determining user comfort with percentage UCI. The improved transfer function used in the proposed EBGWO algorithm performs faster in optimizing nonlinear objective problems. The electricity price in the peak hours is high compared to the off-peak hours. The proposed EBGWO algorithm shift and schedules the loads from the peak hours to off-peak hours, and incorporating SPV in satisfying the user comfort loads aids in reducing the power consumption from the utility during peak hours. Thus, the proposed EBGWO algorithm greatly helps the consumer side decrease the peak-to-average ratio (PAR), improve user comfort significantly, reduce the peak demand, and save the institution's electricity cost by USD 653.046.
\end{abstract}

Keywords: smart grid; institutional loads; reinforced demand-side management; load-shifting; user comfort index; enhanced binary gray wolf optimization

\section{Introduction}

Demand-side management (DSM) is a very promising approach in a smart grid environment to minimize the energy consumption for the consumer and minimize the energy generation for the utility. The DSM algorithms and schemes include energy conservation programs, energy efficiency programs, and demand response (DR) programs. In the literature, there are different methods in which DSM has been implemented. Different types of the load management system have been implemented, such as a scheduling mechanism for interruptible loads over $16 \mathrm{~h} \mathrm{[1],} \mathrm{a} \mathrm{load-shifting} \mathrm{based} \mathrm{DSM} \mathrm{controller} \mathrm{for}$ different categories of load in a residential area, commercial area, and industrial area [2], 
a day-ahead load scheduler with user preference data has been developed for different classes of loads [3], a load-shifting based scheduler for the privacy protection of user energy consumption behavior [4], and a scheduler for controllable residential loads [5]. Different DSM schemes have been proposed for residential consumers, such as an intelligent residential energy management system (IREMS) [6], an optimization model for the operation of a residential microgrid in the presence of various distributed energy sources [7], and a real-time pricing scheme and progressive pricing scheme for smart grid system involving renewable energy resources [8].

The major objectives of DSM include minimization of the cost of energy consumption $[1,3-6,8]$, reduction of peak demand [3,8], minimization of user dissatisfaction $[1,4,5,8]$, and reduction of peak-to-average ratio PAR [3]. Minimizing the total annual cost of microgrids and total annual emission was acheived in [7]. In addition, the reduction in the distance between the actual load consumption curve and the optimized load consumption curve has been described in [2]. The major constraints handled are the maximum power demand limit [6], operational constraints of the loads, dynamics of renewable energy resources $[6,8]$, battery constraints, and economic constraints.

A robust nonlinear controller used for a stand-alone DC microgrid with a battery, a photovoltaic panel (PV), and a supercapacitor [9] and the power flow through the tie-line is typically regulated at a prescheduled value, thereby enforcing the individual microgrid to manage their respective load at steady-state [10]. Theoretical graph analysis is presented to analyze per unit load sharing among all the nodes. The stability of the proposed controller is analyzed considering multiple source nodes using Lyapunov's approach [11]. Some of the load scheduling mechanisms in residential buildings have been reviewed. An intelligent universal load management scheduler (IULMS) can handle different power loads for a real-time residential apartment in India [12]. Exploring the possible demand response and load reduction opportunities under the smart grid for residential electricity load profile [13]. In [14], an intelligent residential load management system (IRLMS) can handle the dynamics of different types of residential loads.

Some of the research work has been focused on the scheduling of specific appliances. A load manager for scheduling the charging duration for electric vehicles (EV) and airconditioners (AC) has been proposed in [15]. A stochastically formulated methodology used for modeling and analyzing the load demand in a domestic distribution system [16]. Distributed DSM systems were implemented based on the artificial immune network algorithm for air conditioning devices to meet the desired demand to tackle the peak load problem [17]. The effect of installing renewable energy sources also has been studied. The impact of wind energy penetration in the scheduling of reserves and energy in a smart distribution system was studied in [18]. A two-stage optimal scheduler was formulated for distributed generation sources in [19]. Demand response potential and characteristics of smart buildings load play a pivotal role in DR programs [20].

The role of educational buildings towards energy consumption across the world also has attracted researchers, and it is being explored. Long short-term memory (LSTM) based energy consumption forecasting model has been formulated in an academic building at IIT Bombay, India [21]. The institutional lab instruments are effectively managed to save energy and estimating the energy efficiency of educational loads [22]. The relation between using energy and space has been investigated for an educational building in Australia using multiple linear regression models in [23]. The optimal design and economical aspects of grid-interactive PV system configuration for an educational campus have been carried out using hybrid optimization of multiple electric renewable (HOMER) software [24]. The load pattern of energy consumption has been studied for Motilal Nehru national instituteof technology (MNNIT), Allahabad, India, using a bottom-up load model [25]. Artificial intelligence techniques are also proposed to solve the energy demand planning in smart homes [26]. The dynamic performance of the energy management schemes is compared based on demand response programs [27]. Demand-side management is used with the PV and the thermal energy storage for peak electric load- shifting [28]. In general, the reach of 
meta-heuristics algorithms is wide in computer scientists and researchers of other fields. The simplicity, flexibility, derivation-free mechanism, and local optimum avoidance made meta-heuristic algorithms more popular. The proposed RDSM technique deploys a GWO, enhancing its transfer function [29]. A game theory-based decentralized control strategy and a game theory-based fuzzy are developed to address the demand-side management problems [30]. Binary Gray Wolf Optimization [31] and Improved Binary Grey Wolf Optimization [32] approaches are used for solving non-linear problems. A demand-side management approach with user satisfaction is implemented for an institutional building [33]. An approach for cost optimization and is capable of giving maximum satisfaction to the user based on the predetermined user budget for an institutional building [34]. A coordinated load scheduling and controlling algorithm have been used to schedule the controllable appliances to minimize the peak load consumption [35]. A virtual queue stability-based Lyapunov optimization technique is employed for real-time energy and comfort optimization in grid-connected solar integrated smart buildings [36]. An innovative home appliance scheduling (IHAS) framework is proposed based on the fusion of the gray wolf and crow search optimization (GWCSO) algorithm to the cost of electricity reduction and user-comfort maximization [37]. A combinatorial heuristic-based profoundsearch algorithm (CHPSA) has been proposed for solving transmission expansion planning (TEP) problems in electric power networks considering wind power penetration [38]. Optimal power flow (OPF) is an important tool in the planning and operation of the power systems and aims to optimize the operational costs. The proposed fuzzy adaptive hybrid configuration oriented to a joint self-adaptive particle swarm optimization (SPSO) and differential evolution (FAHSPSO-DE) algorithms is very effective and robust for solving the OPF problem [39].

To date, from the literature review conducted, there are different methods of implementing DSM in DC microgrids, residential buildings, educational buildings, specific loads, and scheduling the various generation sources. Most of the previous DSM approaches were carried on residential, commercial and industrial loads, whereas DSM approaches for educational loads are less.

The RDSM technique is proposed to achieve the following objectives for the institution:

- Minimize the electricity consumption cost;

- Modeling a separate class of loads for air conditioners (AC);

- Significant reduction in PAR and peak demand;

- Shifts and schedules the institutional loads optimally by considering the constraints;

- User comfort index (UCI) is introduced that helps in increasing the user's satisfaction level for certain non-critical loads by incorporating the SPV.

The paper is organized as follows: Section 2 provides the proposed architecture of the RDSM-EBGWO algorithm. Section 3 presents the mathematical representation of the different classifications of load. Section 4 provides the problem formulation, objective function and constraints. Section 5 provides the details of the optimization algorithm. Section 6 provides implementing the proposed methodology with institutional user input data. Section 7 provides the results and discussion of the different cases. Section 8 presents the conclusion of the paper and enlightens on possible directions for future research.

\section{Novelty}

The DSM techniques for scheduling the loads are more common and popular in residential, industrial and commercial sectors. Educational institutions need DSM strategies to curtail their energy consumption significantly so that annual electricity costs are minimized. The RDSM is proposed for the educational institution Kamaraj College of Engineering and Technology (KCET), Tamil Nadu, India.

- The proposed reinforced demand-side management-enhanced binary gray wolf optimization (RDSM-EBGWO) approach shifts and schedules KCET institutional load optimally, accomplishing the main objective of minimizing the electricity consumption cost. 
- $\quad$ Proposed a dedicated class for temperature-controlled loads, i.e., the air conditioner is modeled using the proposed RDSM-EBGWO, as this type of load contributes $80 \%$ of overall peak demand.

- Formulation of an index termed as user comfort index (UCI) to measure the degree of user's comfort before and after deployment of the proposed RDSM-EBGWO control.

- A $30 \mathrm{~kW}$ solar PV at the institutional premises is integrated into the UCI to increase the percentage of UCI. This lowers the energy consumption from the utility minimizing the electricity consumption cost.

- Performance comparison using metrics, such as peak-to-average ratio (PAR), reduction in peak demand and the cost savings was analyzed with binary particle swarm optimization (BPSO), binary gray wolf optimization (BGWO) and enhanced binary gray wolf optimization (EBGWO) algorithms.

\section{Architecture}

\subsection{Proposed Architecture of RDSM-EBGWO}

The main objective of the proposed RDSM-EBGWO is to curtail the total electricity cost by shifting and scheduling the institutional loads. The RDSM-EBGWO controller also helps in the improvisation of the institutional load consumption profile and UCI. To accomplish the objectives mentioned above, the load profile of KCET is studied and is categorized into four classes, namely uncontrollable non-shiftable loads (UNSLs), controllable Nonshiftable loads (CNSLs), uncontrollable shiftable loads (USLs), and controllable shiftable loads (CSLs).

UNSLs are loads that are fully uncontrollable and left for the user's choice. The UNSLs loads are a fan, lights, chargers, elevators, and local area network (LAN) communication, which are also called critical loads. The details, such as power consumption, period of operation, start and end time of the loads, are fetched from a separate UNSLs status collector. The architecture monitors whether the power consumption simultaneously exceeds the maximum demand limit (MDL). If the UNSLs loads exceed the MDL limit, a warning message is given to the particular load type.

Temperature-dependent loads such as air conditioners (ACs), water heaters, space heaters, geysers, etc., are classified under CNSLs. In this paper, only cooling loads are modeled, as cooling loads contribute to $95 \%$ of the temperature-dependent loads in KCET. The proposed RDSM-EBGWO controller has a dedicated status collector to monitor and $\log$ the parameters of ACs. The parameters collected by the CNSL status collector, such as setpoint temperature, the actual temperature at the instant of operation, tolerance limit, and AC cycle time, are shown in Figure 1. With these values, the RDSM-EBGWO controller shifts and schedules the operation of ACs optimally. The cycle time of AC is the number of times the AC switches ON/OFF within an hour of operation. An ideal AC, on average, has its cycle time as 4, i.e., AC switches ON/OFF every $15 \mathrm{~min}$ for an hour. The normal cycle time for the proper functioning of an AC on average is 4 times in an hour. When this cycle time is either increased or decreased, the efficiency of the AC diminishes or the AC malfunctions. The status collector sends a warning message to the RDSM-EBGWO controller whenever the cycle time of AC exceeds the limit.

The tolerance limit of $\mathrm{AC}$ is affected by the following:

- Ambient temperature;

- Human ambulation;

- Climate, weather, and season;

- Cycle time.

These factors affect the tolerance limit cycle time of AC and play a major role in scheduling the AC. The cycle time affects the power consumption of AC to an ample level. Figure 1 is a pictorial representation of the parameters and factors involved in the modeling of class 2 . 


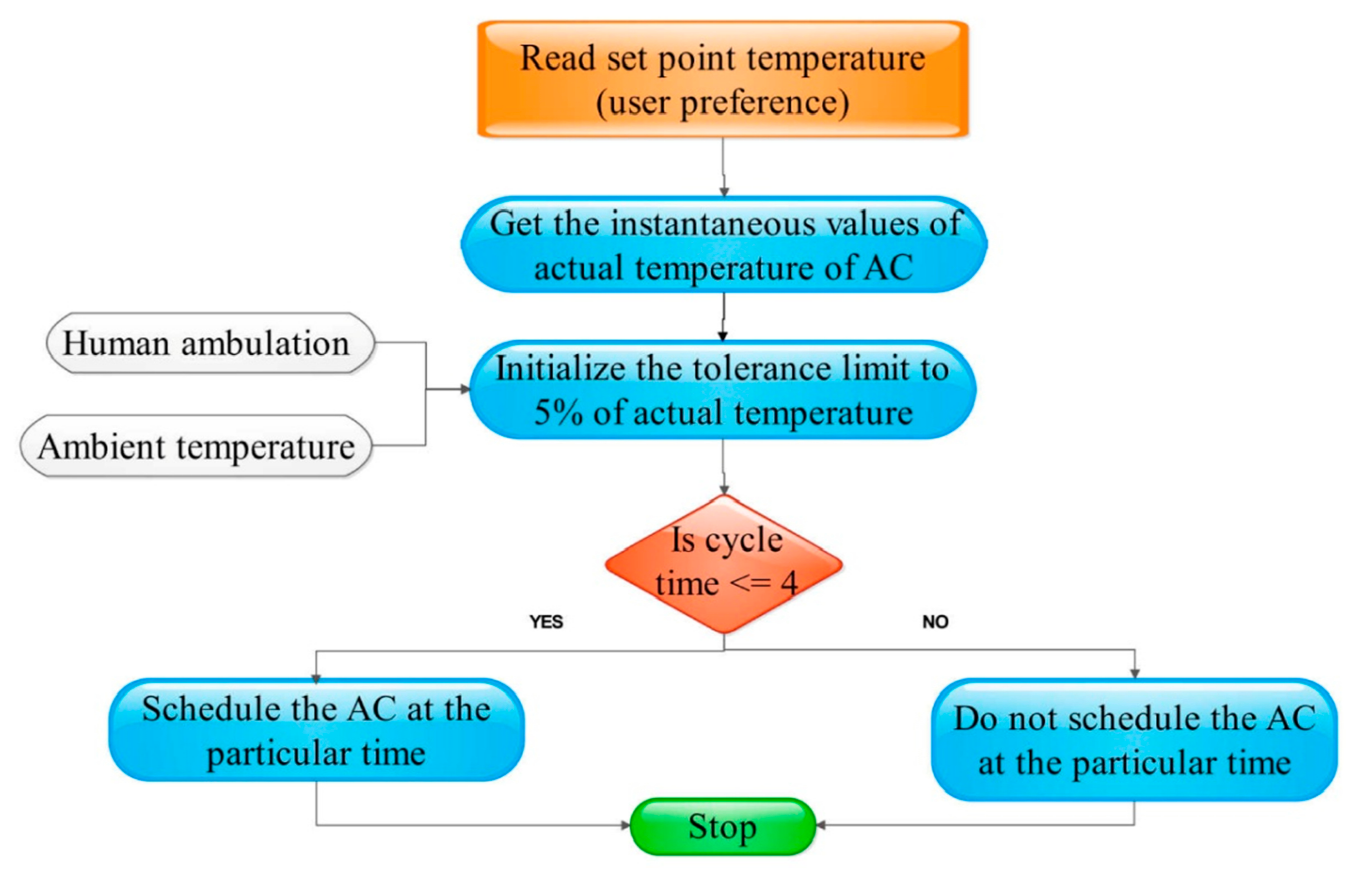

Figure 1. Modeling of CNSL.

The loads that can be controlled, shifted, and operated either continuously or discontinuously within its period of operation are categorized as shiftable loads (SLs). The shiftable loads are further classified as continuously operating uncontrollable shiftable loads (USLs) and discontinuously operating controllable shiftable loads (CSLs). Devices like inverters, batteries are categorized in USLs, which can be scheduled but cannot be interrupted during its period of operation. Laboratory loads, Plug-in hybrid vehicles, Pumps, compressors, etc., are modeled under CSLs that can be interrupted during its period of operation. The USL and CSL have separate status collectors that collect the status of the device and enlist them in their respective categories.

Figure 2 depicts the architecture of the proposed RDSM-EBGWO that has a separate control for each category of load types classified. The smart meters installed at the institutional premises collect the values of the parameters like the demand of the devices, instantaneous power drawn from the utility, etc. These values are logged in some data loggers to store and retrieve data as and when it is needed. With the parameters and data collected status collector marks the status of the device, and the RDSM-EBGWO controller uses this information to shift and schedule the devices optimally.

\subsection{User Comfort Loads (UCLs)}

The main motive of the proposed RDSM approach is to reduce the peak demand, thereby minimizing the electricity consumption cost. At the same time, the user's comfort is also important for certain load types. The loads, such as ceiling fans, DC fans, LED lamps, compressors, and pure water pumps, are considered user comfort loads. The shifting and scheduling of these loads increase the user's dissatisfaction level. To increase the comfort level of these load types, solar PV generation (SPV) is associated with the proposed RDSM architecture. A $30 \mathrm{~kW} \mathrm{SPV} \mathrm{was} \mathrm{set} \mathrm{up} \mathrm{in} \mathrm{the} \mathrm{institutional} \mathrm{premises} \mathrm{that} \mathrm{supply} \mathrm{the} \mathrm{user}$ comfort loads, thus considerably decreasing the power consumed from the utility. This approach increases the user's satisfaction level by increasing the user comfort index (UCI), which indicates the satisfaction level of users for the particular load type. 


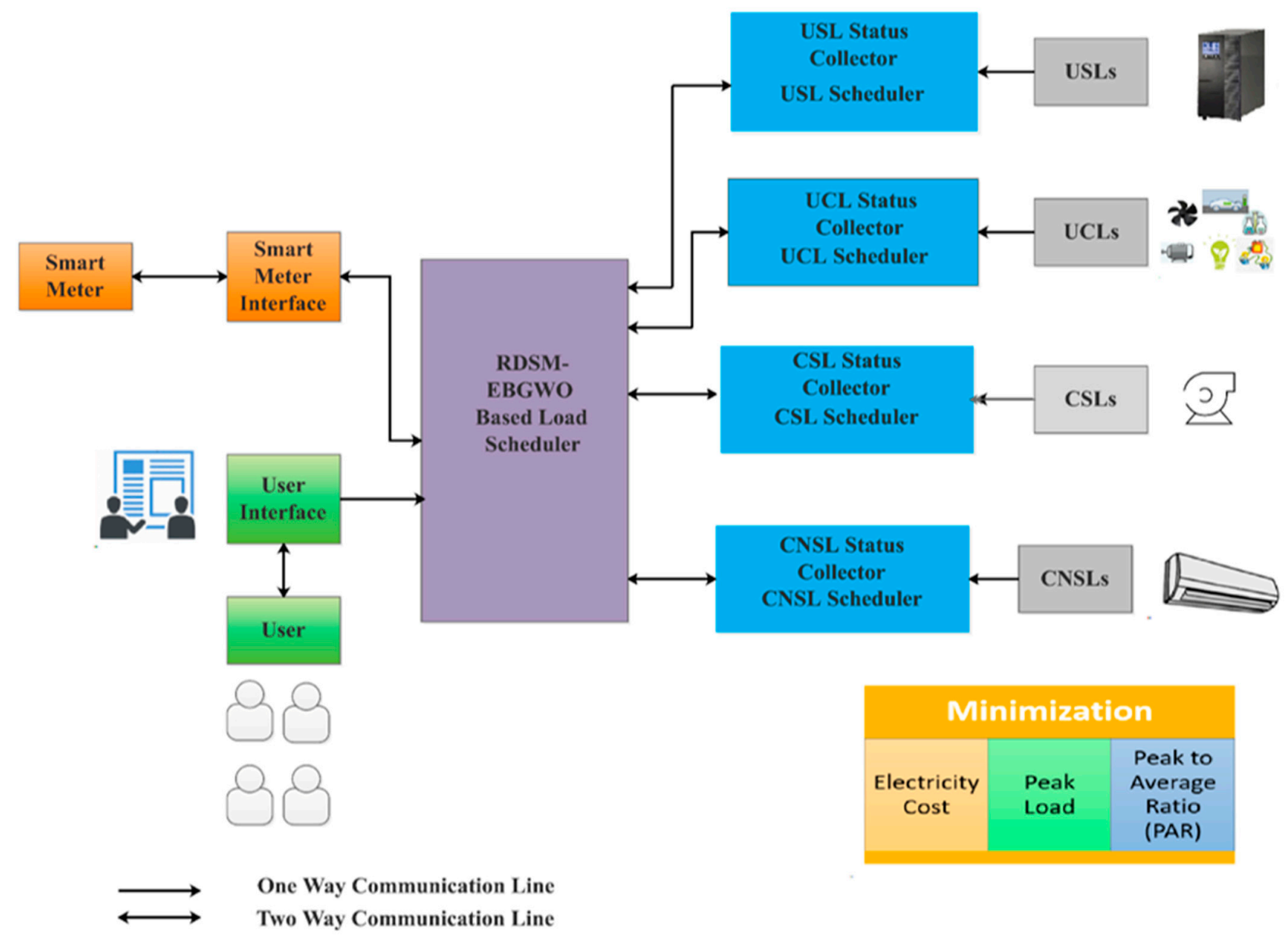

Figure 2. Architecture of the proposed RDSM-EBGWO.

\section{Models of Load}

The institutional demand data of KCET was considered for the analysis in this work. The loads are categorized into four major classes: uncontrollable non-shiftable loads (UNSLs), controllable non-shiftable loads (CNSLs), uncontrollable shiftable loads (USLs), and controllable shiftable loads (CSLs) along with SPV generation and plug-in electric vehicles (PHEVs). The institutional loads with load type and load name are enlisted in Appendix A. The various loads are classified and shown in Figure 3. The load types, Ideal working time with the start time (st) and end time (et), the effective period of operation, classification of load, power consumption and their category of either controlled or uncontrolled is tabulated in Table 1.

\subsection{Modeling the UNSLs}

The operating pattern of these user-controlled loads purely depends on the ON/OFF switching of the user at a given time in a day. The architecture model proposed sums up the demand for this type of load in an hour and ensures the demand does not exceed the sanctioned hourly demand. Let $A$ represents the collection of UNSLs loads. The status vector represents the ON/OFF position of an UNSLs $a(a \in A=[1,2,3, \ldots, A])$ in every interval $(i \in I=[1,2, \ldots, 24])$ is mentioned as:

$$
Y_{a}=\left[y_{a}^{1}, y_{a}^{2}, \ldots \ldots \ldots, y_{a}^{i}, \ldots, y_{a}^{24}\right] \forall a \in A
$$

Here $A$ represents the total number of (UNSL) loads, and $I$ represent the whole number of scheduling intervals on an entire day $(i=24)$. 


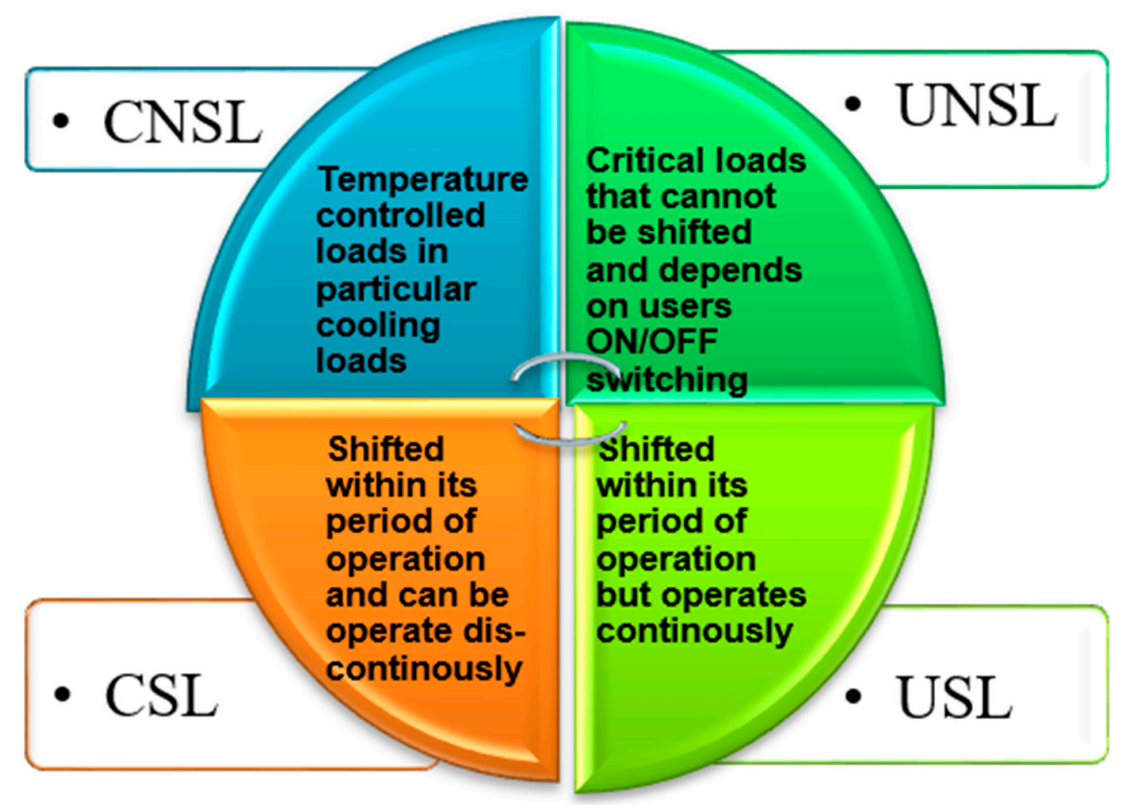

Figure 3. Classification of load types.

Table 1. Load types and their parameters specified.

\begin{tabular}{|c|c|c|c|c|c|}
\hline Load Type & Ideal Working Time (st,et) & Period of Operation & Class & Power $(\mathrm{kW})$ & $\begin{array}{l}\text { Uncontrollable } \\
\text { (U)/Controllable (C) }\end{array}$ \\
\hline 1 & $(9,16)$ & 5 & 1 & 0.055 & U \\
\hline 2 & $(8,16)$ & 6 & 4 & 0.055 & C \\
\hline 3 & $(10,17)$ & 3 & 4 & 287.09 & C \\
\hline 4 & $(1,23)$ & 12 & 4 & 0.013 & C \\
\hline 5 & $(9,20)$ & 6 & 4 & 2.5 & C \\
\hline 6 & $(9,16)$ & 5 & 2 & 7.45 & C \\
\hline 7 & $(9,16)$ & 5 & 2 & 0.003 & C \\
\hline 8 & $(8,16)$ & 2 & 1 & 3.5 & $\mathrm{U}$ \\
\hline 9 & $(1,23)$ & 12 & 1 & 7.5 & $\mathrm{U}$ \\
\hline 10 & $(9,16)$ & 6 & 1 & 5.5 & U \\
\hline 11 & $(5,10)$ & 4 & 4 & 1.5 & $\mathrm{C}$ \\
\hline 12 & $(5,10)$ & 3 & 4 & 2.2 & $\mathrm{C}$ \\
\hline 13 & $(6,10)$ & 2 & 4 & 3.7 & $\mathrm{C}$ \\
\hline 14 & $(8,17)$ & 6 & 4 & 96.42 & C \\
\hline 15 & $(9,16)$ & 3 & 4 & 120.8 & $\mathrm{C}$ \\
\hline 16 & $(9,16)$ & 4 & 4 & 38 & C \\
\hline 17 & $(9,16)$ & 5 & 4 & 39 & C \\
\hline 18 & $(9,16)$ & 5 & 4 & 3.27 & C \\
\hline 19 & $(9,16)$ & 3 & 4 & 64.7 & C \\
\hline 20 & $(9,16)$ & 5 & 4 & 28 & C \\
\hline 21 & $(9,16)$ & 5 & 4 & 37 & C \\
\hline 22 & $(9,16)$ & 6 & 4 & 13 & C \\
\hline 23 & $(9,16)$ & 4 & 4 & 32.9 & C \\
\hline 24 & $(9,16)$ & 3 & 4 & 17.4 & C \\
\hline 25 & $(9,16)$ & 5 & 4 & 51.06 & C \\
\hline 26 & $(9,16)$ & 5 & 4 & 39.9 & C \\
\hline 27 & $(9,16)$ & 2 & 4 & 39 & C \\
\hline 28 & $(9,16)$ & 5 & 4 & 103.99 & C \\
\hline 29 & $(9,16)$ & 5 & 4 & 0.5 & C \\
\hline 30 & $(8,15)$ & 1 & 4 & 2.5 & C \\
\hline 31 & $(9,16)$ & 1 & 3 & 2.5 & U \\
\hline 32 & $(9,16)$ & 2 & 4 & 2.5 & C \\
\hline 33 & $(9,16)$ & 1 & 4 & 2.5 & C \\
\hline 34 & $(9,16)$ & 1 & 4 & 2.5 & C \\
\hline
\end{tabular}




\subsection{Model of CNSLS}

The operating pattern of this type of load is temperature-dependent. These types of loads consume high power when in operation and less power when in STANDBY mode. In this paper, the cooling load is modeled by taking the frequency of the ON/OFF cycle of the air conditioner (ACs) into consideration. In other words, the frequency of the cycle for an hour of AC operation is counted for the efficient behavior of the device.

Let $A$ denote the set of CNSLs, and I denote the set of monitoring intervals of nonshiftable loads (UNSLs and CNSLs). The operating vector representing the ON/OFF status of an CNSLs $b(b \in B \Delta=[1,2, \ldots, B])$ in each interval $i(i \in I \Delta=[1,2, \ldots, I])$ is defined as:

$$
Y_{b}=\left[y_{b}^{1}, y_{b}^{2}, \ldots \ldots \ldots, y_{b}^{i}, \ldots, y_{b}^{24}\right] \forall b \in B
$$

where $I$ is the total number of non-shiftable load intervals in a day. Given the setpoint temperature, allowable tolerance limit, and frequency of cycle of operation of CNSL b as $t_{s e t}^{b}, t_{\text {tol }}^{b}$ and $C y c l e_{b}^{i}$, respectively. The actual temperature at the end of the interval $(i-1)$ as $t(i-1)_{a c t}^{b}$ the desired operating status of $b$ during the interval $i$ can be described as follows:

$$
Y_{b}^{i}=\left\{\begin{array}{c}
1, \text { if } t_{\text {set }}^{b}>\left(t_{\text {set }}^{b}+t_{\text {tol }}^{b}\right) \text { And }\left(C y c l e_{b}^{t}==4\right) \\
0, \text { if }\left(t(i)_{a c t}^{b}<t_{\text {set }}^{b}\right) \text { And }\left(\left(C y c l e_{b}^{i}>4\right) \text { Or }\left(C y c l e_{b}^{i}<4\right)\right) \\
Y_{b}^{(i-1)}, \text { if } t_{\text {set }}^{b} \leq t(i)_{a c t}^{b} \leq\left(t_{\text {set }}^{b}+t_{\text {tol }}^{b}\right)
\end{array}\right\}
$$

The ON/OFF switching cycle frequency for cooling is once per $15 \mathrm{~min}$ of operation. Thus, in an hour, the cycle frequency for a normal operating cooling load is 4 . The device malfunctions or consumes more power below or above this limit. However, the frequency of the cycle of operation differs with some models of ACs.

\subsection{Model of SLs}

The loads, which have higher feasibility of shifting in operation time, are modeling in this category. These are schedulable loads, which hardly rely on user comfort. There is high freedom in shifting these types of loads so that the peak load can be reduced, and cost savings can be increased considerably. The shiftable loads are further classified as uncontrollable shiftable loads (USLs) and controllable shiftable loads (CSLs).

\subsubsection{Model of USLs}

Schedulable loads that can only be operated continuously within their period of operation are categorized as uncontrollable shiftable loads. Let $C$ represents the set of uninterruptible loads. The status vector represents the ON/OFF position of a USLs $c$ ( $c \in C$ $=[1,2, \ldots, C])$ on every interval is $(i \in I=[1,2, \ldots, 24])$ mentioned as:

$$
Y_{c}=\left[y_{c}^{1}, y_{c}^{2}, \ldots \ldots . ., y_{c}^{i}, \ldots, y_{c}^{24}\right] \forall c \in C
$$

where $C$ is the total number of uncontrollable loads. These loads can be operated continuously within the start time (st) and the end time (et) to satisfy the load operating period. The operation status of USLs load $c$ for interval $i$ is mentioned as:

$$
y_{c}^{i}=\left\{\begin{array}{c}
0, i<s t_{c} \text { and } i>e t_{c} \\
1, s t_{c} \leq i \leq e t_{c} \text { and } n_{c}{ }^{i} \leq d_{c} \\
\text { and }\left[s t_{c}: e t_{c}\right]=d_{c}
\end{array}\right.
$$

where

$s t_{c}=$ start time for load $c$;

et $t_{c}=$ end time for load $c$;

$s t_{c}: e t c=$ operating range from the start time to the end time; 
$n_{c}{ }^{i}=$ total number of load $c$ operating hours to $i$ th interval;

$d_{c}=$ load $c$ operating duration (in the total number of hours).

\subsubsection{Model of CSLs}

Loads that are schedulable but can be operated discontinuously within their period of operation in slots are categorized as controllable shiftable loads. Let $D$ represents the controllable shiftable loads. The status vector represents the ON/OFF position of CSLs $d$ $(d \in D=[1,2,3, \ldots, D])$ in every interval $(i \in I=[1,2,3, \ldots, 24])$ is defined as:

$$
Y_{d}=\left[y_{d}^{1}, y_{d}^{2}, \ldots \ldots \ldots, y_{d}^{i}, \ldots, y_{d}^{24}\right] \forall d \in D
$$

where $D$ is the number of controllable loads. These loads can be operated intermittently within the start time (st) and end time (et) for satisfying the load operating duration. The operating position of a CSL load $d$ for interval $i$ is:

$$
y_{d}^{i}=\left\{\begin{array}{c}
0, i<s t_{d} \text { and } i>e t_{d} \\
1, s t_{d} \leq i \leq e t_{d} \text { and } n_{d}^{i} \leq d_{d} \\
\text { and }\left[s t_{d}: e t_{d}\right]=d_{d}
\end{array}\right.
$$

where

$s t_{d}=$ start time for load $d$;

$e t_{d}=$ end time for load $d$;

$s t_{d}, e t_{d}=$ operating range from the start time to the end time;

$n_{d}{ }^{i}=$ total number of load $d$ operating hours to the $i$ th interval;

$d_{d}=$ load $d$ operating duration (in the total number of hours).

\section{Problem Formulation}

A novel reinforced demand-side management (RDSM) technique was formulated for accomplishing the main objective of minimizing electricity cost and improving user comfort considerably. The problem formulated help in optimally shifting and scheduling the loads with the developed enhanced binary gray wolf optimization (EGBWO) algorithm for demand at the institutional load.

\subsection{Objective Function}

The leading objective of the proposed RDSM-EBGWO approach is to achieve minimum electricity cost by optimally shifting and scheduling the institution loads while also acknowledging the user's comfort. The nonlinearity and dynamic nature of the real-time electricity pricing and the demand variations of the loads make the objective function also a nonlinear function. The formulated objective function is stated in Equation (8):

$$
\text { Min : Cost }=\sum_{i=1}^{24} \sum_{r=1}^{n} S_{r}(i) \times P D_{r} \times \operatorname{Rate}(i)
$$

where $i$ represents the hour of operation, which varies from 1 to 24 , i.e., $24 \mathrm{~h}$ of a day $n$ is the total number of load types considered for modeling that varies from 1 to $n$. Further,

$S_{r}(i)=$ status of load $r$ at the $i$ th hour of operation, i.e., ON is 1 or OFF is 0 ;

$P D_{r}=$ power demand for the $r$ th load; and

Rate $(i)=$ electricity price at the $i$ th hour of operation. 


\subsection{Constrains}

\subsubsection{Load Duration}

All the shiftable and non-shiftable loads are scheduled for $24 \mathrm{~h}$ of a day to satisfy their load duration. The load duration is the period of operation that the device type is expected to operate:

$$
\text { subject to } \sum_{i=1}^{24} \sum_{r=1}^{n} S_{r}(i)=d_{r}
$$

where $d_{r}=$ number of operating hours of load type " $r$ ".

\subsubsection{Total Daily Load Demand}

The demand for loads shifted and scheduled for $24 \mathrm{~h}$ per day should be equal to the total daily demand of loads before scheduling:

$$
\text { subject to } \sum_{i=1}^{24} \sum_{r=1}^{n} D_{1}(i)_{r}=\sum_{i=1}^{24} \sum_{r=1}^{n} D_{2}(i)_{r}
$$

where $D_{1}(i)_{r}$ is the total daily demand before shifting at the $i$ th hour of $r$ th type of load, $D_{2}(i)_{r}$ is the total daily demand after shifting at the $i$ th hour of $r$ th type of load.

\subsubsection{Power Demand at Any Instant}

The power demand by the user at any time must be near or equal to maximum power demand. This is shown in Equation (11):

$$
P D_{i} \leq P D_{\text {max }} \forall i €[1,24]
$$

where $P D_{i}=$ power demand at the $i$ th hour of the day; $P D_{\max }=$ maximum power demand limit (MPDL) sanctioned.

The constraint is termed MPDL. It ensures that the maximum power demand does not exceed the programmed limit.

\subsubsection{Idle Constraint}

The devices should remain idle other than their operating period. This is referred to as idle constraint, as shown in Equation (12):

$$
S_{r}(i) \forall i<s t, i>e t \text { and } i €[1,24] r €[1, n]
$$

$S_{r}(i)=$ status of load $r$ at the $i$ th hour of operation, i.e., $\mathrm{ON}$ is 1 or $\mathrm{OFF}$ is 0.

\section{Optimization Algorithm}

\subsection{Binary Gray Wolf Optimization}

Mirjalili et al. [25] created a new evolutionary algorithm known as gray wolf optimization $(\mathrm{GWO})$ based on wolves' hunting behavior. In this algorithm, alpha $(\alpha)$ is considered as the fittest solution, beta $(\beta)$ and delta $(\delta)$ are the second and third fittest solutions correspondingly. The remaining solutions are presumed as omega $(\omega)$. There are four different groups in the gray wolf pack: alpha, beta, delta, and omega. The alpha male makes decisions in hunting, selecting resting and sleeping places, etc. The rest of the family must obey its decisions. The dominant male alpha is placed at the top of the family pyramid. The mathematical model of the encircling behavior is presented in the following Equations (13) and (14):

$$
\begin{gathered}
\vec{D}=\left|\vec{C} \cdot \vec{X}_{p}(t)-\vec{X}(t)\right| \\
\vec{X}(t+1)=\vec{X}_{p}(t)-\vec{A} \cdot \vec{D}
\end{gathered}
$$


where $t$ is the current iteration, $A$ and $C$ are coefficient vectors, $X_{p}$ is the position vector of the prey, and $X$ indicates the position vector of a gray wolf. The coefficient vectors $A$ and $C$ are calculated using Equations (15) and (16) as follows:

$$
\begin{gathered}
\vec{A}=2 \vec{a} \cdot \overrightarrow{r_{1}}-\vec{a} \\
\vec{C}=2 \cdot \overrightarrow{r_{2}}
\end{gathered}
$$

where components of " $\boldsymbol{a}$ " are linearly decreased from 2 to 0 throughout iterations, and $\boldsymbol{r}_{\mathbf{1}}$ and $\boldsymbol{r}_{2}$ are random vectors in [0,1]. Emary et al. [26] introduced two methods for the binary version of GWO to choose the optimal feature subset for feature classification. In the first method, the updating equation of the particle position is framed as:

$$
\vec{X}(t+1)=\operatorname{Crossover}\left(\vec{X}_{1}, \vec{X}_{2}, \vec{X}_{3}\right)
$$

Crossover $(x, y, z)$ is the suitable crossover between solutions $x, y, z$, and $X_{1}, X_{2}, X_{3}$. The binary vectors represent the movement of wolves towards alpha, beta, and delta gray wolves. In the second method, the updating equation of the particle position is mentioned as:

$$
\vec{X}(t+1)=\left\{\begin{array}{c}
1 \text { if sigmoid }\left(\frac{\vec{X}_{1}+\vec{X}_{2}+\vec{X}_{3}}{3}\right) \\
0 \text { otherwise }
\end{array}\right.
$$

The initial population in the BGWO algorithm is set as 200 , and the maximum number of iterations is 300 . The algorithm is considered to be converged when the fitness value does not change in 50 iterations, and the alpha position is set as the best schedule in the final iteration. The BGWO algorithm's solution vector for each load type is a [1 $\times 24]$ vector:

$$
P_{\mathrm{BGWO}}=\left[s_{1} s_{2} s_{3} \ldots \ldots \ldots \ldots s_{24}\right]
$$

where $P_{\mathrm{BGWO}}=\mathrm{BGWO}$ algorithm's solution vector;

$S_{k}=$ load type " $k$ " status $=1(\mathrm{ON})$ or $0(\mathrm{OFF})$.

Equation (19) shows the BGWO algorithm with the fitness function. It will return the bit vector for every load type with the optimized minimum cost.

\subsection{Enhanced Binary Gray Wolf Optimization}

Pei $\mathrm{Hu}$ et al. [32] proposed an enhanced binary gray wolf optimization (EBGWO), which is the improved version of the binary gray wolf algorithm (BGWO). The proposed EBGWO has the following enhancements:

- An improved " $a$ " parameter is proposed, which plays a vital role in controlling the A and D influencing the exploration and exploitation;

- The proposed new transfer function and the updating equation for the " $a$ " parameter balances the abilities of the global and local search of the algorithm.

The transfer function is the simplest method in the binary GWO, which maps the continuous values to [0,1] and then discretizes them to 0 and 1 according to the probability. BGWO uses the $S 1$ transfer function as stated in Equation (20):

$$
S 1=1 /\left(1+e^{-10\left(A^{d} \cdot D^{d}-0.5\right)}\right)
$$

BGWO is known to use $S 1$ as the transfer function. The transfer function is a key part of the binary GWO and is an easy method to control the exploration and exploitation of the algorithm. Three new $V$-type transfer functions are introduced by Pei Hu proposed 
to enhance the functionality of BGWO. Equations (21)-(23) give details for the $V$ transfer functions. Equation (24) details the " $a$ " parameter:

$$
\begin{gathered}
V 1=(x) \mid / \text { tanh } \tanh (4) \\
V 2=\mid \sqrt{17} \times \frac{x}{\left(4 \times \sqrt{\left(1+x^{2}\right)} \mid\right.} \\
V 3=\left|\left(\frac{2}{\pi} x\right) / \arctan (2 \pi)\right| \\
a=2 \times \text { it/max_it }
\end{gathered}
$$

where $i t=$ iteration and max_it = maximum iteration. In Equation (24), " $a$ " increases linearly from 0 to 2 . All three $V$-type transfer functions were deployed to the test system considered to find which transfer function gives optimal results.

\section{Implementation}

\subsection{Proposed Methodology}

The proposed reinforced demand-side management (RDSM) aids to optimally schedule loads by deploying the new enhanced binary gray wolf optimization algorithm (EBGWO). The loads are categorized into four classes, which have separate status collectors linked with the main RDSM-EBGWO controller. Initially, RDSM is fed with the details of the total load data of the institution and the real-time electricity pricing. The RDSM-EBGWO monitors and controls the load data based on the constraints stated in Section 4.2. Figure 4 details the flow of the proposed methodology.

\subsection{Real-Time System}

Demand-side management (DSM) is highly adopted by the consumer side, especially in the residential and institutional category of consumers. The proposed RDSM-EBGWO technique was implemented with the real-time system of KCET. In general, there are seven working hours for an educational institution, from 09:00 to 16:00. Within these $7 \mathrm{~h}$, 09:00 to 12:00 is considered peak working hours in which real-time electricity pricing is also high. The main objective of the proposed methodology was to shift the loads from the peak hours to off-peak hours so that the electricity cost and peak demand will dwindle to a significant level. The electricity price in the peak hours, i.e., from 09:00 to 12:00, is higher than the off-peak hours. The peak pricing of USD 27.35/kWh at 10:00 and USD 8.11/kWh at 02:00 is the lowest in the off-peak hours.

\subsection{User Input Data}

The case study environment for the proposed methodology at KCET was initially studied without setting up the proposed RDSM-EBGWO techniques to perceive the peak demand and scheduling of the load. The input data were user-specified, and parameters like start time, end time, number of devices operated, period of operation and power $(\mathrm{kW})$ are taken as input. As stated in Section 3, the category of classes was based on both periods of operation and the user's input. In this work, 34 different load types were considered, the use times and operation periods of which are tabulated in Table 2. 


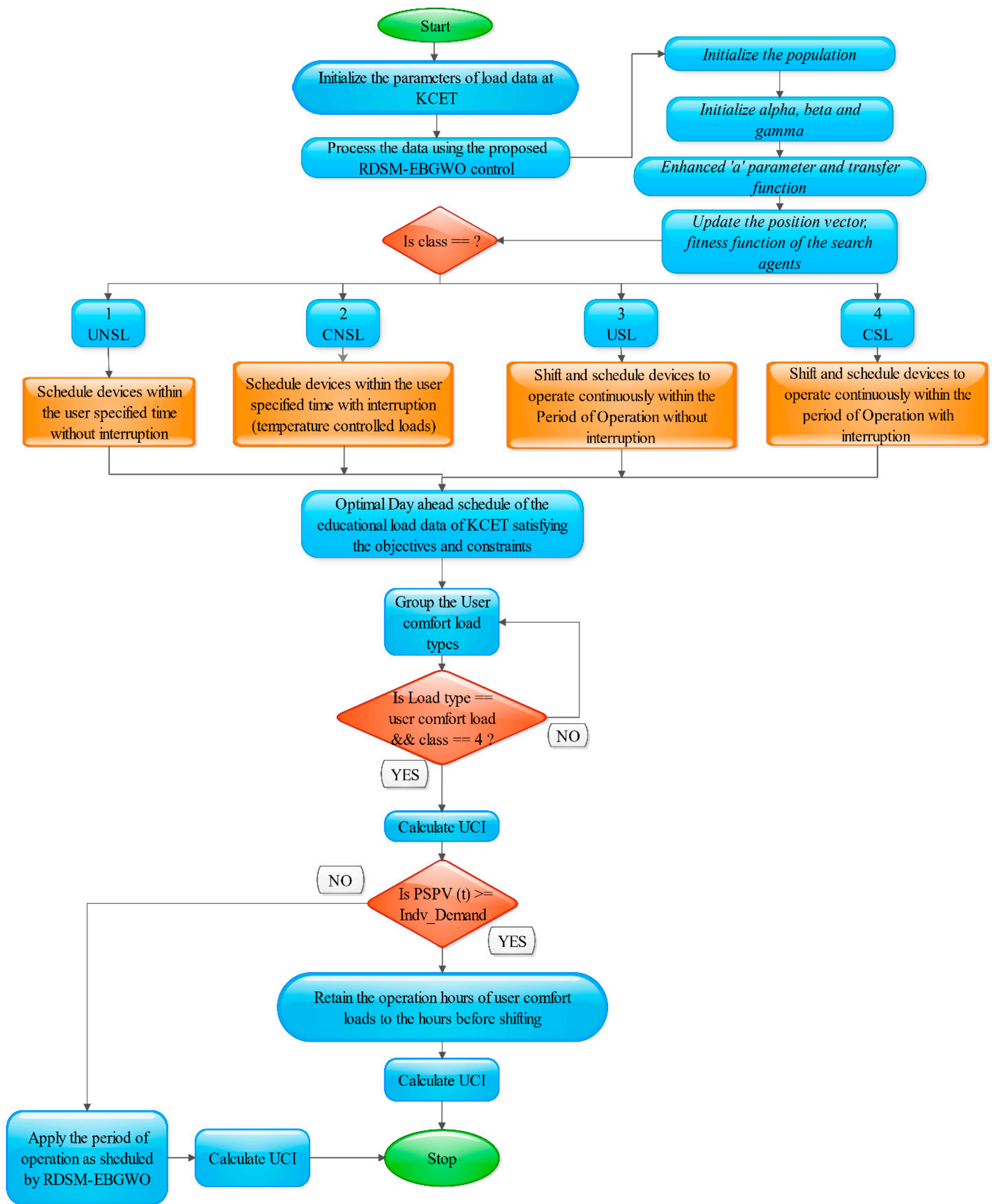

Figure 4. Flowchart of the proposed RDSM-EBGWO. 
Table 2. Time of use of equipment.

\begin{tabular}{|c|c|c|c|}
\hline Load Type & Equipment & Period of Operation & Time of Use of Equipment \\
\hline 1 & Ceiling fan 1 & 5 & $(9,10,11,12,13)$ \\
\hline 2 & Ceiling fan 2 & 6 & $(9,10,12,13,14,16)$ \\
\hline 3 & DC fan & 3 & $(14,15,17)$ \\
\hline 4 & Lights & 12 & $(1,2,4,5,7,12,15,16,18,19,20,21)$ \\
\hline 5 & LED lamps & 6 & $(10,12,14,15,18,19)$ \\
\hline 6 & 1 phase AC & 5 & $(11,12,13,14,15)$ \\
\hline 7 & 3 phase $\mathrm{AC}$ & 5 & $(14,15,16,17,18)$ \\
\hline 8 & Chargers & 2 & $(6,7)$ \\
\hline 9 & LAN communication & 12 & $(8,9,10,11,12,13,14,15,16,17,18,19)$ \\
\hline 10 & Elevator & 6 & $(8,9,10,11,12,13)$ \\
\hline 11 & Compressor 1 & 4 & $(5,6,8,10)$ \\
\hline 12 & Sewage and water pumps & 3 & $(7,9,10)$ \\
\hline 13 & Compressor 2 & 2 & $(8,9)$ \\
\hline 14 & Pure water pump & 6 & $(8,11,12,14,15,16)$ \\
\hline 15 & Polymer lab & 3 & $(9,11,16)$ \\
\hline 16 & Machine shop & 4 & $(11,12,15,16)$ \\
\hline 17 & Computer east load & 5 & $(10,11,13,14,16)$ \\
\hline 18 & Computer west load & 5 & $(10,11,13,14,15)$ \\
\hline 19 & Chemistry lab & 3 & $(12,13,14)$ \\
\hline 20 & Electrical lab & 5 & $(9,10,12,14,15)$ \\
\hline 21 & Mechanical lab & 5 & $(9,10,11,15,16)$ \\
\hline 22 & Admin & 6 & $(9,11,12,13,14,15)$ \\
\hline 23 & EIE & 4 & $(12,13,14,15)$ \\
\hline 24 & Polymer testing & 3 & $(13,14,16)$ \\
\hline 25 & ECE lab & 5 & $(10,11,12,14,15)$ \\
\hline 26 & Computer lab & 5 & $(9,11,14,15,16)$ \\
\hline 27 & Library lab & 2 & $(10,13)$ \\
\hline 28 & Biotech lab & 5 & $(9,11,12,14,16)$ \\
\hline 29 & IT lab & 5 & $(10,11,13,14,16)$ \\
\hline 30 & Invertors & 1 & 14 \\
\hline 31 & PHEV charging1 & 1 & 9 \\
\hline 32 & PHEV charging 2 & 2 & $(10,11)$ \\
\hline 33 & PHEV charging 3 & 1 & 11 \\
\hline 34 & PHEV charging 4 & 1 & 14 \\
\hline
\end{tabular}

\section{Results and Discussion}

\subsection{Demand without DSM}

The study of the scheduling of loads without incorporating any DSM or DR techniques plays a vital role in wisely categorizing and shifting the critical and non-critical loads to accomplish the desired objective of cost minimization. The electricity cost at 10:00 was observed to be USD $26.82 / \mathrm{kWh}$, which was marked as the peak electricity pricing. The demand at off-peak hours was lower without load scheduling, which aided in shifting the load demands from peak hours to off-peak hours, reducing the electricity cost.

\subsection{Case 1-Implementation of the Proposed RDSM-EBGWO}

For the real-time system considered, the peak demand was very high without the RDSM-EBGWO controller. The proposed RDSM-EBGWO control identified the CSL load types and shifted them optimally from peak hours to off-peak hours, thus reducing the peak demand from $1855.468 \mathrm{~kW}$ to $384.17 \mathrm{~kW}$, which reduced the electricity consumption cost from USD 2030.67 to USD 1377.63. Consider a CSL load type 4 whose individual power demand was $287.09 \mathrm{~kW}$. Without implementing RDSM strategy, this lighting load operated at $(9,10,11,12,13,14,15,16,17,18,19,20)$ hours with $12 \mathrm{~h}$ being its period of operation. The RDSM-EBGWO controller shifted the load type 4 to $(1,2,4,5,7,15,16,17,18,19,20,21)$.

Figure 5 shows the hourly demand of the four classes considered. The shifting of the load type 4 ensured that the proposed RDSM-EBGWO controller was capable of 
identifying the CSL load types. The proposed control algorithm was also efficient in shifting and scheduling the load types in off-peak hours. The peak pricing hours from 09:00 to 13:00 were shifted to 01:00 to 07:00, thus reducing the electricity cost by USD 653.05.

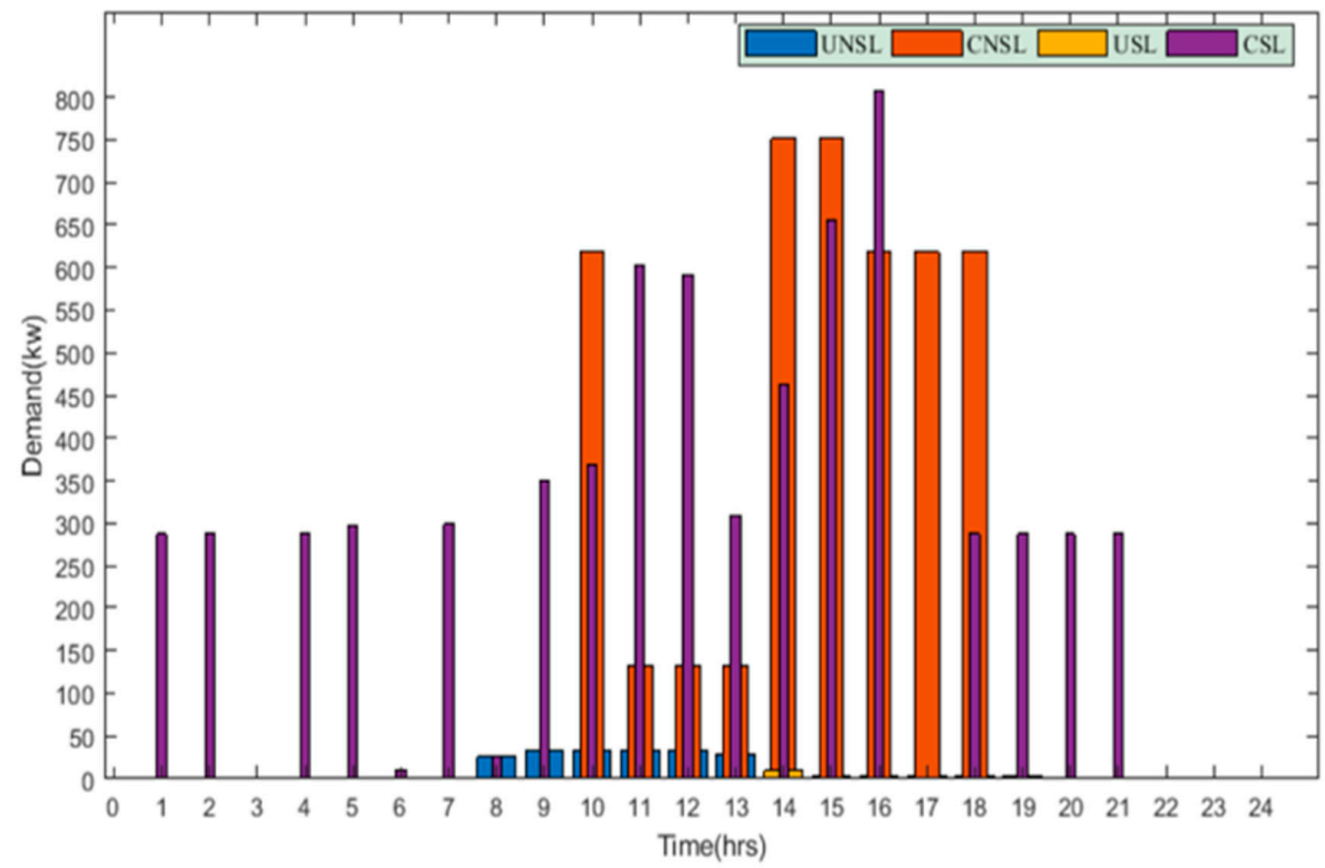

Figure 5. Hourly scheduling of loads based on the four categories of classes.

To test the optimality of the proposed EBGWO algorithm, two more swarm-based algorithms were deployed to the real-time system considered. They were binary particle swarm optimization (BPSO) and binary gray wolf algorithm (BGWO).

Table 3 shows various parameters of the PAR value and electricity cost after implementing the algorithm, and Table 4 details the obtained values of peak-to-average ratio (PAR), peak demand, electricity cost and its reduction with and without DSM. The reduction in PAR was 0.866 in BPSO, which was increased to 1.6989 after implementing EBGWO. The proposed RDSM-EBGWO had the highest cost savings of USD 653.046 compared to USD 612.396 and USD 562.99 that were the cost savings of BPSO and BGWO, respectively. Figure 6 shows the energy demand graph for before and after DSM with various optimization algorithms.

Table 3. PAR and cost values after implementing algorithms.

\begin{tabular}{cccccccccc}
\hline \multirow{2}{*}{ Criteria } & \multicolumn{3}{c}{ BPSO } & \multicolumn{3}{c}{ BGWO } & \multicolumn{3}{c}{ EBGWO } \\
\cline { 2 - 10 } & Best & Mean & SD & Best & Mean & SD & Best & Mean & SD \\
\hline PAR Value & 3.263 & 3.2562 & 0.0073 & 2.7356 & 2.6477 & 0.0802 & 2.4297 & 2.4169 & 0.0109 \\
Electricity Cost (USD) & 1467.67 & 1488.76 & 8.627 & 1418.27 & 1436.22 & 6.91 & 1377.63 & 1382.46 & 3.99 \\
\hline
\end{tabular}

Table 4. Comparison result for before and after implementation of algorithms.

\begin{tabular}{|c|c|c|c|c|c|c|c|c|c|}
\hline \multirow{3}{*}{ Criteria } & \multicolumn{3}{|c|}{ BPSO } & \multicolumn{3}{|c|}{ BGWO } & \multicolumn{3}{|c|}{ EBGWO } \\
\hline & \multicolumn{3}{|c|}{ Parameters } & \multicolumn{3}{|c|}{ Parameters } & \multicolumn{3}{|c|}{ Parameters } \\
\hline & PAR & $\begin{array}{c}\text { Peak } \\
\text { Demand }\end{array}$ & $\begin{array}{l}\text { Electricity } \\
\text { Cost (USD) }\end{array}$ & PAR & $\begin{array}{c}\text { Peak } \\
\text { Demand }\end{array}$ & $\begin{array}{l}\text { Electricity } \\
\text { Cost (USD) }\end{array}$ & PAR & $\begin{array}{c}\text { Peak } \\
\text { Demand }\end{array}$ & $\begin{array}{l}\text { Electricity } \\
\text { Cost (USD) }\end{array}$ \\
\hline Without DSM & 4.129 & 1855.47 & 2030.67 & 4.1286 & 1855.47 & 2030.67 & 4.1286 & 1855.47 & 2030.67 \\
\hline With DSM & 3.263 & 1502.238 & 1467.678 & 2.7356 & 1229.42 & 1418.27 & 2.4297 & 1091.97 & 1377.63 \\
\hline Reduction & 0.866 & 353.23 & 562.9902 & 1.3930 & 626.0480 & 612.396 & 1.6989 & 763.4980 & 653.046 \\
\hline$\%$ Reduction & 20.98 & 19.0372 & 27.7244 & 33.741 & 33.7407 & 30.1573 & 41.149 & 41.1485 & 32.1592 \\
\hline
\end{tabular}




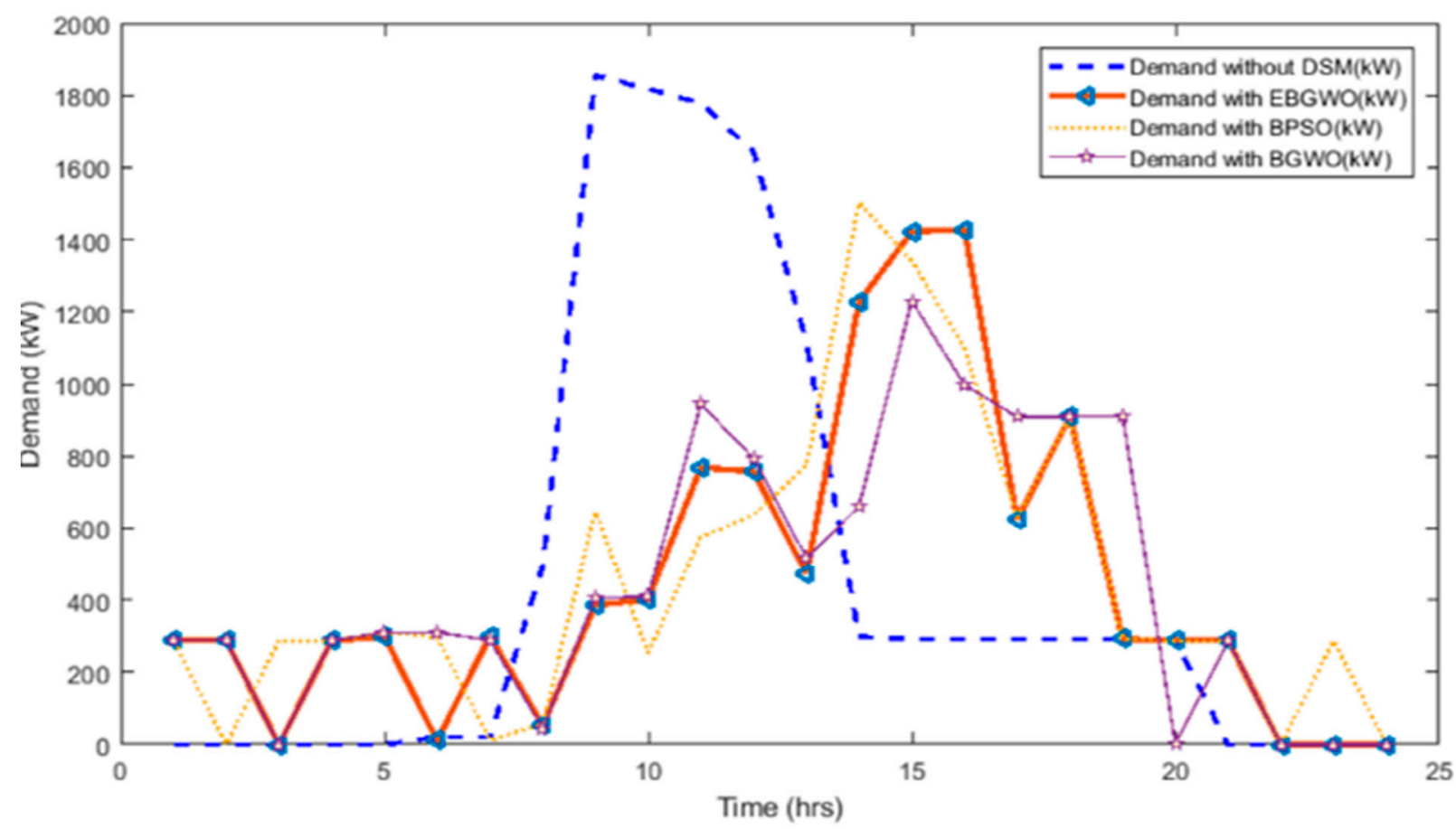

Figure 6. Demand before and after DSM with various optimization algorithms.

\subsection{Case 2-Analysis of User Comfort Index (UCI)}

The shifting of loads from the unscheduled time to the time slots after deploying optimization algorithms discomforts the user. Before deploying the RDSM-EBGWO based controller, the loads were scheduled to the user's preferences and comfort. The proposed controller shifted and scheduled these loads optimally to accomplish the objective of cost reduction. Even though the objective is reached, the comfort index of users decreased.

Table 5 details the period of operation both before and after deployment of the RDSMEBGWO controller. The user comfort index (UCI) was obtained using the period of operation of the loads as in Equation (25):

$$
\% U C I=\left(\frac{\text { Number of Non }- \text { shifted hours of period of operation }}{\text { Total number of hours of the Period of operation }}\right) \times 100
$$

Table 5. Period of operation of user comfort loads before and after deployment of RDSM-EBGWO controller.

\begin{tabular}{cccc}
\hline Load Type & $\begin{array}{c}\text { Before Deploying } \\
\text { RDSM-EBGWO Controller }\end{array}$ & $\begin{array}{c}\text { After Deploying } \\
\text { RDSM-EBGWO Controller }\end{array}$ & $\begin{array}{c}\text { Number of Non-Shifted Hours of Period } \\
\text { of Operation }\end{array}$ \\
\hline $\mathbf{2}$ & $(8,9,10,11,12,13)$ & $(9,10,12,13,14,16)$ & 4 \\
$\mathbf{3}$ & $(9,10,11)$ & $(14,15,17)$ & 0 \\
$\mathbf{5}$ & $(8,9,10,11,12,13)$ & $(10,12,14,15,18,19)$ & 2 \\
$\mathbf{1 1}$ & $(9,10,11,12)$ & $(5,6,8,10)$ & 1 \\
$\mathbf{1 3}$ & $(6,7)$ & $(8,9)$ & 0 \\
$\mathbf{1 4}$ & $(9,10,11,12,13,14)$ & $(8,11,12,14,15,16)$ & 3 \\
\hline
\end{tabular}

The time of operation of each user comfort loads before and after scheduling is shown in Figures 7 and 8, respectively. 

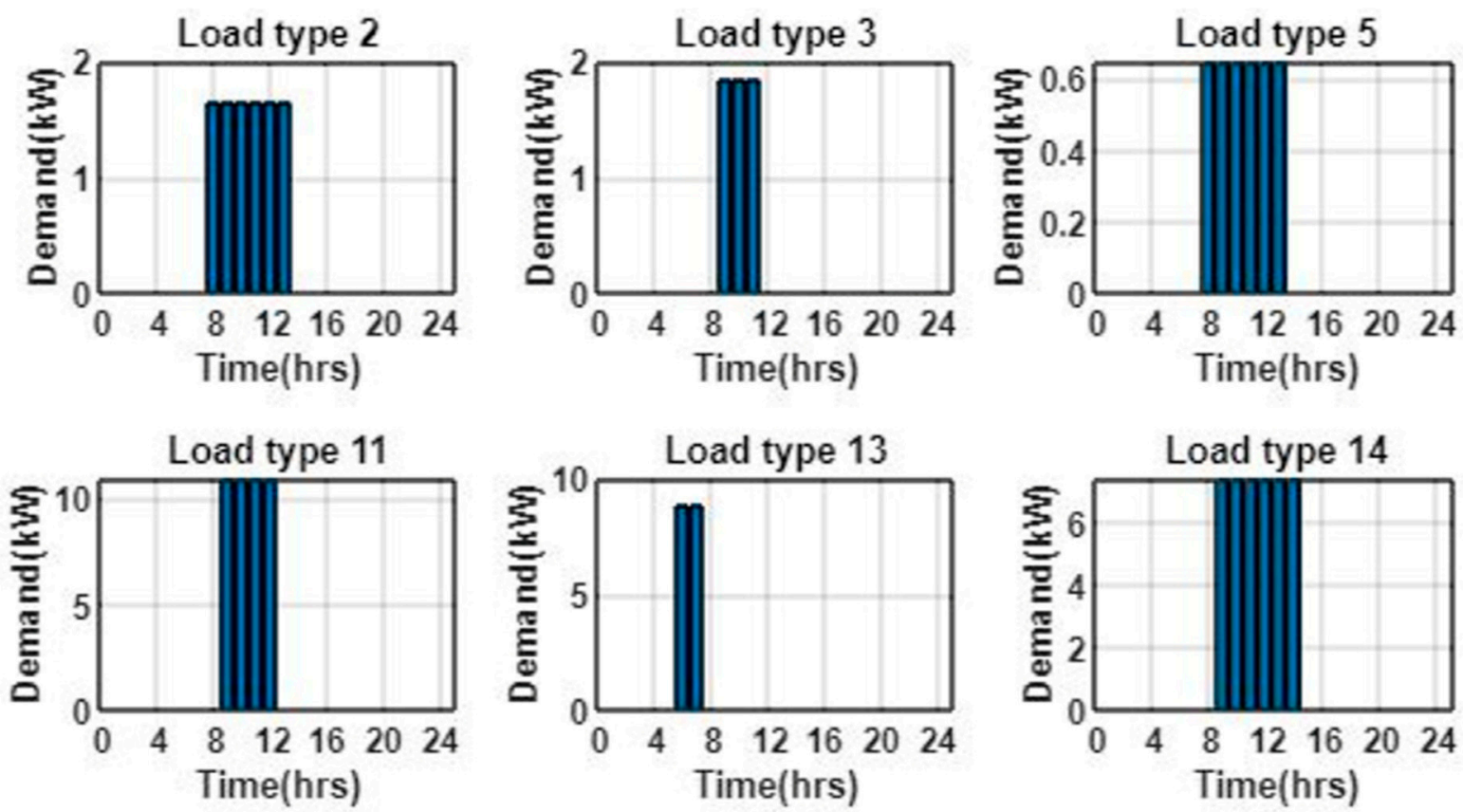

Figure 7. Unscheduled operation of user comfort load before deployment of DSM.
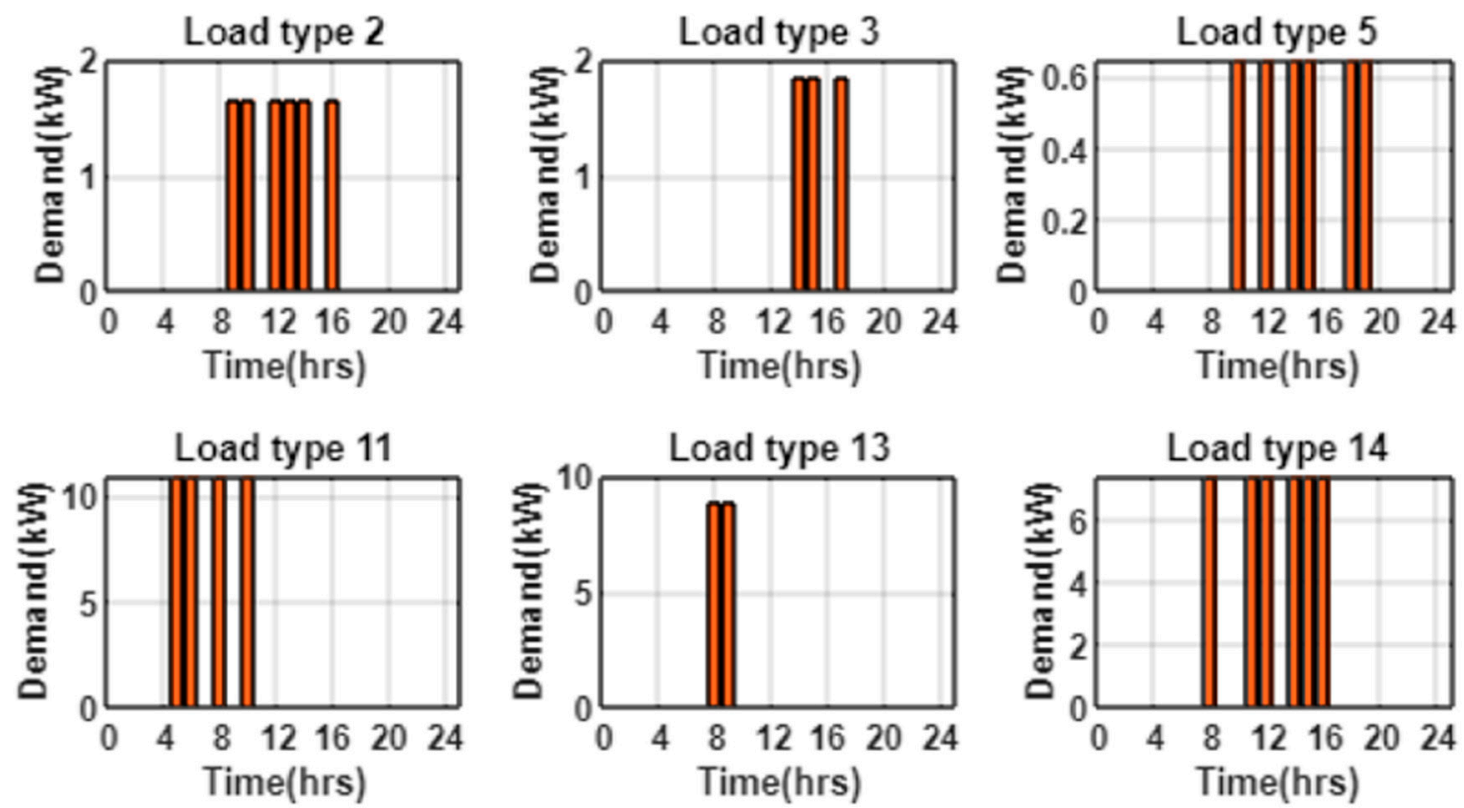

Figure 8. Scheduled operation of user comfort load after deploying the proposed EBGWO.

Consider the load types: 3-DC fans and 13-compressors used in the college premises. The percentage of UCI of both loads 3 and 13 before deployment of the RDSMEBGWO controller was $100 \%$ and was now reduced to $0 \%$. This means that the period of operation of both the loads before deployment of the RDSM-EBGWO controller was completely different from that after deployment of the RDSM-EBGWO controller. This type of shifting of loads discomforted the users. The comfort was increased by retaining the period of operation as per users' desire. These loads were supplied by the solar PV instead of the utility supply so that this supports accomplishing the main objective of cost curtailment. After incorporating solar with these user comfort loads, the percentage of UCI of load types 3 and 13 were made $100 \%$ by retaining its period of operation as per user desire. Table 6 details the percent UCI of each load type considered as user comfort loads. 
Table 6. User comfort index (UCI) before and after deployment of RDSM-EBGWO.

\begin{tabular}{cccc}
\hline Load Type & $\begin{array}{c}\text { Before Deployment of } \\
\text { RDSM-EBGWO (\%) }\end{array}$ & $\begin{array}{c}\text { After Deployment of } \\
\text { RDSM-EBGWO (\%) }\end{array}$ & $\begin{array}{c}\text { Increased Percentage of UCI Using } \\
\text { Solar PV Generation (\%) }\end{array}$ \\
\hline $\mathbf{2}$ & 100 & 66.7 & 33.3 \\
$\mathbf{3}$ & 100 & 0 & 100 \\
$\mathbf{5}$ & 100 & 33.3 & 66.7 \\
$\mathbf{1 1}$ & 100 & 25 & 75 \\
$\mathbf{1 3}$ & 100 & 0 & 100 \\
$\mathbf{1 4}$ & 100 & 50 & 50 \\
\hline
\end{tabular}

The percentage of UCI of other load types 2,5,11, and 14 increased by $33.3 \%, 66.7 \%$, $75 \%$, and $50 \%$, respectively. The individual demand for these loads was supplied by the $30 \mathrm{~kW}$ solar PV generation set up at KCET. The demand for the user comfort loads before and after RDSMEBGWO is shown in Figure 9. The demand at the eighth hour could be seen shifting from $2.7 \mathrm{~kW}$ to $27.2 \mathrm{~kW}$, and this increase in demand was met by the SPV generation. It can be seen that the increase in UCI, as tabulated in Table 6, is clearly seen in demand increase at each hour in Figure 9.

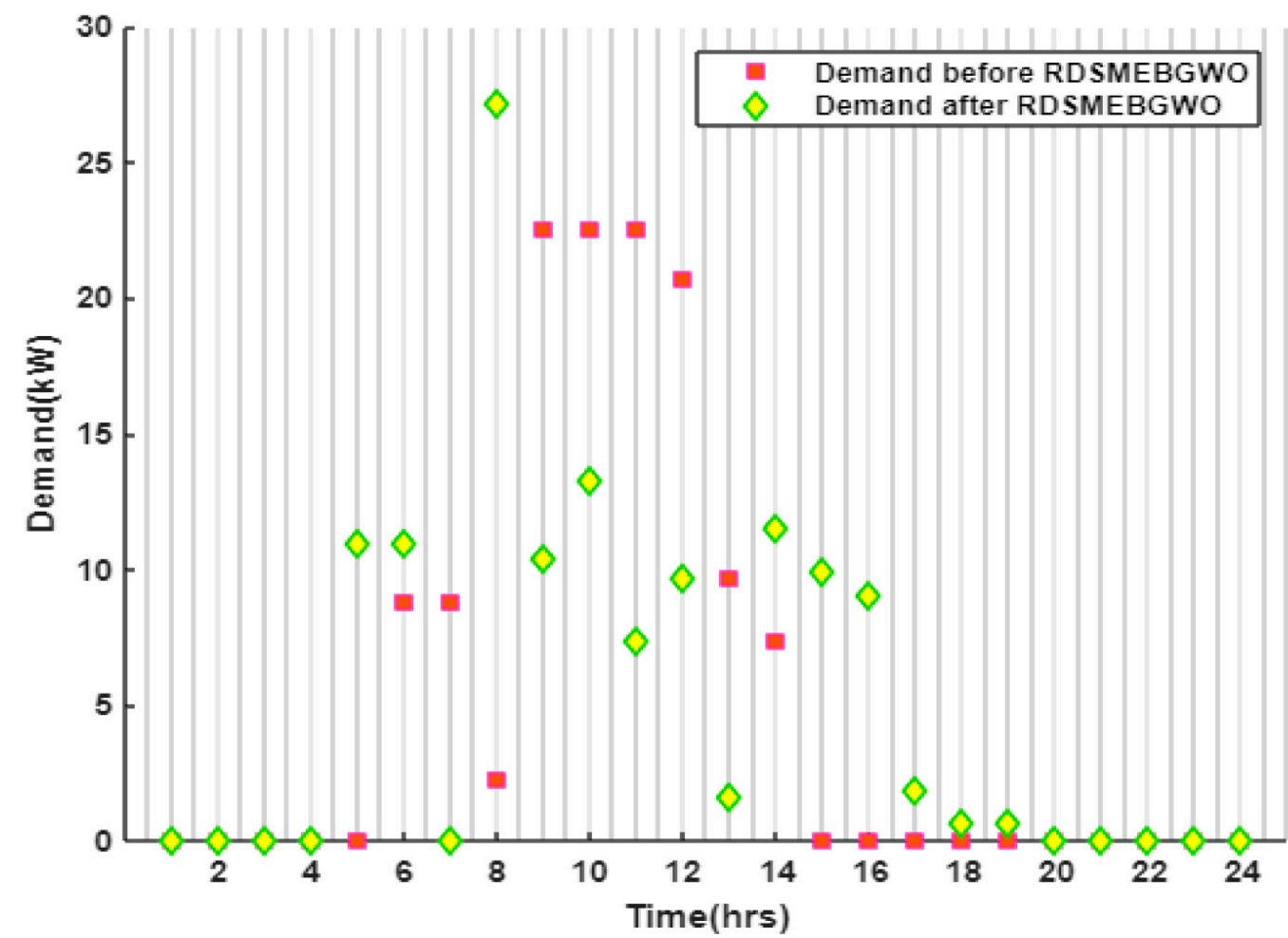

Figure 9. Demand for user comfort loads before and after RDSMEBGWO.

\subsection{Case 3-Temperature Controlled Class}

The class CNSL was modeled for temperature-controlled devices independently. The cooling load considered in this paper was commercial air conditioners (ACs). Tables 7 and 8 details the scheduling and shifting of AC loads and the parameters considered for modeling, respectively. It can be seen that both the single-phase and three-phase ACs were scheduled, neglecting the peak hours, i.e., 9:00 and 10:00, whose electricity pricing was high. As the study was conducted in an institution, the AC loads were shifted within the peak hours with lesser electricity pricing. The shifting of temperature-controlled load types 6 and 7 is detailed in Figure 10. The three-phase AC shifted from $(9,10,11,12,13)$ hours of operation to $(14,15,16,17,18)$ hours that had lesser electricity pricing. Because of this reason, the temperature-controlled load types were categorized under CNSL. 
Table 7. Parameters for modeling temperature-dependent loads.

\begin{tabular}{cccccc}
\hline Load Type & Number of Devices & Ideal Working Time & Demand (kW) & Equipment & Shifted Hours of Operation \\
\hline 6 & 53 & {$[9,16]$} & 30 & 1-phase AC & {$[11,12,13,14,15]$} \\
7 & 83 & {$[9,16]$} & 35 & 3-phase AC & {$[14,15,16,17,18]$} \\
\hline
\end{tabular}

Table 8. Factors affecting the temperature-dependent load.

\begin{tabular}{cc}
\hline Setpoint Temperature & $\mathbf{2 4 . 0}{ }^{\circ} \mathbf{C}$ \\
\hline Actual temperature & $\begin{array}{c}\text { Instantaneous values of temperature within the } \\
\text { period of operation of the equipment }\end{array}$ \\
$\begin{array}{c}\text { Tolerance limit (ambient temperature, } \\
\text { human ambulation) } \\
\text { Cycle time }\end{array}$ & $0.05 \%$ of actual temperature \\
& 4 (Section 2) \\
\hline
\end{tabular}
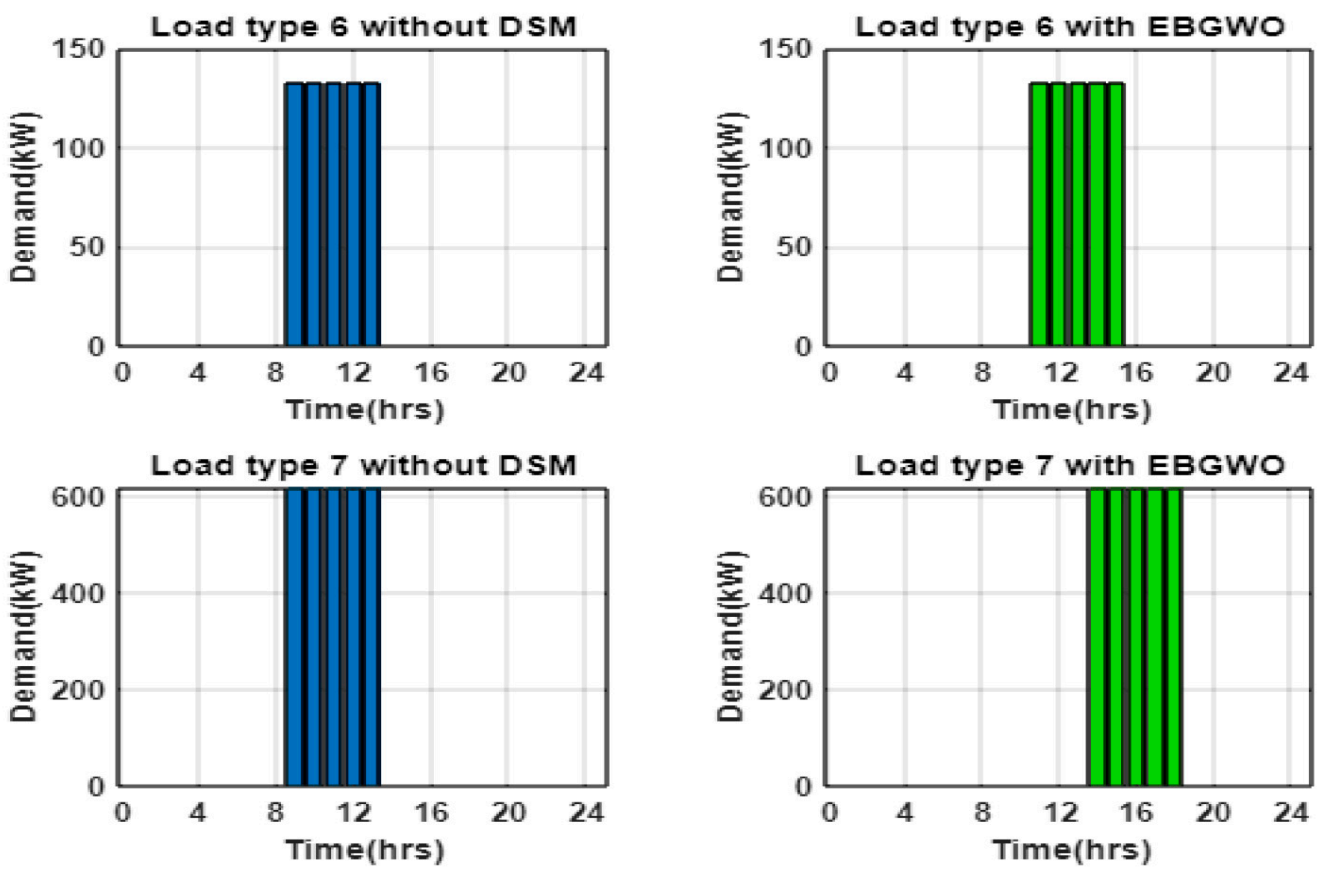

Figure 10. Shifting of load types 6 and 7 without DSM and with the proposed EBGWO.

\section{Conclusions}

The nonlinear objective function was effectively handled by the proposed RDSMEBGWO algorithm, which was implemented in a real-time institutional load, accomplishing the following main objectives:

- Minimized electricity consumption cost.

- Significant reduction in PAR and peak demand.

- Shifted and scheduled the institutional loads optimally by considering the constraints.

- Modeled a separate class of loads for temperature-controlled air conditioners (AC).

- User comfort index (UCI) was introduced that helped to increase the user's satisfaction level for certain non-critical loads by incorporating the SPV.

- The percentage of electricity cost savings increased from $27.7244 \%$ to $32.1592 \%$ after deployment of BPSO and EBGWO, respectively.

Thus, the determined parameter values, such as peak demand, PAR and electricity cost, ensure that the proposed EBGWO gives the best results among other algorithms. Future work may include various pricing schemes, such as real-time pricing, time of use pricing and critical peak pricing. The DSM implemented with hybrid algorithms can also be developed. 
Author Contributions: Conceptualization, methodology and software, K.T.; writing-original draft and formal analysis, C.R.S.; supervision and visualization, J.D.N.J.; data curation, validation and Investigation, R.M.E.; writing-review and editing, L.M.-P.; All authors have read and agreed to the published version of the manuscript.

Funding: This research received funding from DST—SERB under SRG Scheme (file number: SRG/2019/ 001946).

Institutional Review Board Statement: Not applicable.

Informed Consent Statement: Not applicable.

Data Availability Statement: Not applicable.

Acknowledgments: Authors express their gratitude to the respective institution for support in carrying out this research work. In addition, the financial support from DST-SERB under SRG Scheme (file number: SRG/2019/001946) is gratefully acknowledged.

Conflicts of Interest: The authors declare no conflict of interest.

\section{Appendix A}

\begin{tabular}{|c|c|c|c|}
\hline Load Type & Number of Devices & Class & Load Name \\
\hline 1 & 128 & 1 & Ceiling fan 1 \\
\hline 2 & 30 & 4 & Ceiling fan 2 \\
\hline 3 & 48 & 4 & DC fan \\
\hline 4 & 1 & 4 & Lights \\
\hline 5 & 50 & 4 & LED lamps \\
\hline 6 & 53 & 2 & 1 phase AC \\
\hline 7 & 83 & 2 & 3 phase $\mathrm{AC}$ \\
\hline 8 & 20 & 1 & Chargers \\
\hline 9 & 1 & 1 & LAN communication \\
\hline 10 & 3 & 1 & Elevator \\
\hline 11 & 2 & 4 & Compressor1 \\
\hline 12 & 8 & 4 & Sewage and water pumps \\
\hline 13 & 4 & 4 & Compressor 2 \\
\hline 14 & 2 & 4 & Pure water pump \\
\hline 15 & 1 & 4 & Polymer lab \\
\hline 16 & 1 & 4 & Machine shop \\
\hline 17 & 1 & 4 & Computer east load \\
\hline 18 & 1 & 4 & Computer west load \\
\hline 19 & 1 & 4 & Chemistry lab \\
\hline 20 & 1 & 4 & Electrical lab \\
\hline 21 & 1 & 4 & Mechanical lab \\
\hline 22 & 1 & 4 & Admin \\
\hline 23 & 1 & 4 & EIE \\
\hline 24 & 1 & 4 & Polymer testing \\
\hline 25 & 1 & 4 & ECE lab \\
\hline 26 & 1 & 4 & Computer lab \\
\hline 27 & 1 & 4 & Library lab \\
\hline 28 & 1 & 4 & Biotech lab \\
\hline 29 & 1 & 4 & IT lab \\
\hline 30 & 20 & 3 & Invertors \\
\hline 31 & 5 & 4 & PHEV charging 1 \\
\hline 32 & 5 & 4 & PHEV charging 2 \\
\hline 33 & 5 & 4 & PHEV charging 3 \\
\hline 34 & 5 & 4 & PHEV charging 4 \\
\hline
\end{tabular}




\section{References}

1. Pedrasa, M.A.A.; Spooner, T.D.; MacGill, I.F. Scheduling of Demand Side Resources Using Binary Particle Swarm Optimization. IEEE Trans. Power Syst. 2009, 24, 1173-1181. [CrossRef]

2. Logenthiran, T.; Srinivasan, D.; Shun, T.Z. Demand Side Management in Smart Grid Using Heuristic Optimization. IEEE Trans. Smart Grid 2012, 3, 1244-1252. [CrossRef]

3. Logenthiran, T.; Srinivasan, D.; Phyu, E. Particle swarm optimization for demand side management in smart grid. In Proceedings of the 2015 IEEE Innovative Smart Grid Technologies-Asia (ISGT ASIA), Bangkok, Thailand, 3-6 November 2015; pp. 1-6.

4. Liu, E.; Cheng, P. Achieving Privacy Protection Using Distributed Load Scheduling: A Randomized Approach. IEEE Trans. Smart Grid 2017, 8, 2460-2473. [CrossRef]

5. Zakariazadeh, A.; Jadid, S.; Siano, P. Smart microgrid energy and reserve scheduling with demand response using stochastic optimization. Electr. Power Energy Syst. 2014, 63, 523-533. [CrossRef]

6. Arun, S.L.; Selvan, M.P. Intelligent Residential Energy Management System for Dynamic Demand Response in Smart Buildings. IEEE Syst. J. 2017, 12, 1329-1340. [CrossRef]

7. Bhamidi, L.; Sivasubramani, S. Optimal Planning and Operational Strategy of a Residential Microgrid With Demand Side Management. IEEE Syst. J. 2020, 14, 2624-2632. [CrossRef]

8. Park, L.; Jang, Y.; Cho, S.; Kim, J. Residential Demand Response for Renewable Energy Resources in Smart Grid Systems. IEEE Trans. Ind. Inform. 2017, 13, 3165-3173. [CrossRef]

9. Ravada, B.R.; Tummuru, N.R. Control of a Supercapacitor-Battery-PV Based Stand-Alone DC-Microgrid. IEEE Trans. Energy Convers. 2020, 35, 1268-1277. [CrossRef]

10. Mudaliyar, S.; Duggal, B.; Mishra, S. Distributed Tie-Line Power Flow Control of Autonomous DC Microgrid Clusters. IEEE Trans. Power Electron. 2020, 35, 11250-11266. [CrossRef]

11. Chaturvedi, S.; Fulwani, D.; Guerrero, J.M. Adaptive-SMC Based Output Impedance Shaping in DC Microgrids Affected by Inverter Loads. IEEE Trans. Sustain. Energy 2020, 11, 2940-2949. [CrossRef]

12. Hemanth, G.R.; Raja, S.C.; Nesamalar, J.J.D.; Kumar, J.S. Cost effective energy consumption in a residential building by implementing demand side management in the presence of different classes of power loads. Adv. Build. Energy Res. 2020, 1-26. [CrossRef]

13. Chuan, L.; Ukil, A. Modeling and validation of electrical load profiling in residential buildings in Singapore. 2015 IEEE Power Energy Soc. Gen. Meet. 2015, 30, 2800-2809. [CrossRef]

14. Arun, S.L.; Selvan, M.P. Dynamic demand response in smart buildings using an intelligent residential load management system. IET Gener. Transm. Distrib. 2017, 11, 4348-4357. [CrossRef]

15. Singh, S.; Namboodiri, A.; Selvan, M.P. Agent-based system to control the air-conditioner and EV charging for residents in smart cities. IET Smart Cities 2019, 1, 71-80. [CrossRef]

16. Qian, K.; Zhou, C.; Allan, M.; Yuan, Y. Modeling of Load DemandDue to EV Battery Charging in Distribution Systems. IEEE Trans. Power Syst. 2011, 26, 802-810. [CrossRef]

17. Lizondo, D.; Rodríguez, S.; Will, A.; Jimenez, V.; Gotay, J. An Artificial Immune Network for Distributed Demand-Side Management in Smart Grids. Inf. Sci. 2018, 438, 32-45. [CrossRef]

18. Zakariazadeh, A.; Jadid, S.; Siano, P. Economic-environmental energy and reserve scheduling of smart distribution systems: A multiobjective mathematical programming approach. Energy Convers. Manag. 2014, 78, 151-164. [CrossRef]

19. Qiu, J.; Meng, K.; Zheng, Y.; Dong, Z.Y. Optimal scheduling of distributed energy resources as a virtual power plant in a transactive energy framework. IET Gener. Transm. Distrib. 2017, 11, 3417-3427. [CrossRef]

20. Chen, Y.; Xu, P.; Chen, Z.; Wang, H.; Sha, H.; Ji, Y.; Zhang, Y.; Dou, Q.; Wang, S. Experimental investigation of demand response potential of buildings: Combined passive thermal mass and active storage. Appl. Energy 2020, 280, 115956. [CrossRef]

21. Nivethitha, S.; Gauthama Raman, M.R.; Ramamritham, K. A hybrid model for building energy consumption forecasting using long short term memory networks. Appl. Energy 2020, 261, 114131.

22. Yeo, J.; Wang, Y.; An, A.K.; Zhang, L. Estimation of energy efficiency for educational buildings in Hong Kong. J. Clean. Prod. 2019, 235, 453-460. [CrossRef]

23. Gui, X.; Gou, Z.; Zhang, F. The relationship between energy use and space use of higher educational buildings in subtropical Australia. Energy Build. 2020, 211, 109709. [CrossRef]

24. Shilpa, N.; Sridevi, H.R. Optimum design of Rooftop PV System for An Education Campus Using HOMER. In Proceedings of the 2019 Global Conference for Advancement in Technology (GCAT), Bangalore, India, 18-20 October 2019; pp. 1-4.

25. Basumatary, J.; Pratap Singh, B.; Gore, M.M. Demand Side Management of a University Load in Smart Grid Environment. In Proceedings of the Workshops co-located with the International Conference on Distributed Computing and Networks, Varanasi, India, 4-7 January 2018.

26. Helder, R.O.; Rocha, I.H.; Honorato, R.F.; Wanderley, C.; Celeste, L.J.; Silvestre, J.; Silva, A.L. An Artificial Intelligence based scheduling algorithm for demand-side energy management in Smart Homes. Appl. Energy 2021, 282, $116-145$.

27. Mbungu, N.T.; Bansal, R.C.; Naidoo, R.M.; Bettayeb, M.; Siti, M.W.; Bipath, M. A dynamic energy management system using smart metering. Appl. Energy 2020, 280, 115990. [CrossRef] 
28. Saffari, M.; de Gracia, A.; Fernández, C.; Belusko, M.; Boer, D.; Cabeza, L.F. Optimized demand side management (DSM) of peak electricity demand by coupling low temperature thermal energy storage (TES) and solar PV. Appl. Energy 2018, 211, 604-616. [CrossRef]

29. Mirjalili, S.; Mirjalili, S.M.; Lewis, A. Grey Wolf Optimizer. Adv. Eng. Softw. 2014, 69, 46-61. [CrossRef]

30. Tang, R.; Li, H.; Wang, S. A game theory-based decentralized control strategy for power demand management of building cluster using thermal mass and energy storage. Appl. Energy 2019, 242, 809-820. [CrossRef]

31. Emary, E.; Zawbaa, H.M.; Hassanien, A.E. Binary Gray Wolf Optimization Approaches for Feature Selection. Neurocomputing 2016, 172, 371-381. [CrossRef]

32. Hu, P.; Pan, J.-S.; Chu, S.-C. Improved Binary Grey Wolf Optimizer and Its application for feature selection. Knowl. Based Syst. 2020, 195, 105746. [CrossRef]

33. Rajvikram, M.E.; Leoponraj, S.; Vishnupriyan, J.; Dheeraj, A.; Gangaram, S. Multi-Criteria Decision Analysis for user satisfactioninduced demand-side load management for an institutional building. Renew. Energy 2021, 170, 1396-1426.

34. Rajvikram, M.E.; Leoponraj, S.; Vishnupriyan, J.; Dheeraj, A.; Gangaram, S.; Muhammad, I.; Mahesh, G.K. PV-Diesel-Hydrogen fuel cell based grid connected configurations for an institutional building using BWM framework and cost optimization algorithm. Sustain. Energy Technol. Assess. 2021, 43, 100934.

35. Nilotpal, C.; Arijit, M.; Samrat, M. Efficient Scheduling of Non-Preemptive Appliances for Peak Load Optimization in Smart Grid. IEEE Trans. Ind. Inform. 2017, 8, 3447-3458.

36. Ahmad, A.; Khan, J.Y. Real-Time Load Scheduling, Energy Storage Control and Comfort Management for Grid-Connected Solar Integrated Smart Buildings. Appl. Energy 2019, 259, 114208. [CrossRef]

37. Waseem, M.; Lin, Z.; Liu, S.; Sajjad, I.A.; Aziz, T. Optimal GWCSO-based home appliances scheduling for demand response considering end-users comfort. Electr. Power Syst. Res. 2020, 187, 106477. [CrossRef]

38. Naderi, E.; Pourakbari-Kasmaei, M.; Lehtonen, M. Transmission expansion planning integrated with wind farms: A review, comparative study, and a novel profound search approach. Int. J. Electr. Power Energy Syst. 2020, 115, 105460. [CrossRef]

39. Naderi, E.; Pourakbari-Kasmaei, M.; Cerna, F.V.; Lehtonen, M. A novel hybrid self-adaptive heuristic algorithm to handle singleand multi-objective optimal power flow problems. Int. J. Electr. Power Energy Syst. 2020, 125, 106492. [CrossRef] 